\title{
Induction of $\boldsymbol{N}$-Acetylglucosamine Kinase in Yeast
}

\author{
By A. Bhattacharya, M. Puri and A. Datta \\ School of Life Sciences, Jawaharlal Nehru University, New Mehrauli Road, New Delhi 110057, India
}

(Received 25 March 1974)

\begin{abstract}
The presence of $N$-acetylglucosamine is essential for the induced synthesis of $N$-acetylglucosamine kinase in Candida albicans. The enzyme synthesis stops and its concentration in the cells declines rapidly as soon as $N$-acetylglucosamine is removed from the medium. Experiments with RNA- and protein-synthesis inhibitors indicate that the appearance of new enzyme activity is dependent on concomitant new protein synthesis and the inducer operates at a transcriptional level.
\end{abstract}

$N$-Acetylglucosamine kinase (EC 2.7.1.59), the first enzyme in the metabolism of $N$-acetylglucosamine, is found commonly in animal tissues and bacteria (Zeleznick et al., 1964; Datta, 1970), but its presence in yeast has not previously been demonstrated. We have been able to induce this enzyme in Candida albicans, a pathogenic strain of yeast. This inducible enzyme is absent from cells grown on glucose, but appears when $N$-acetylglucosamine is used as a carbon source in the growth medium. A study of the factors controlling enzyme induction in yeast provides a simple eukaryotic system for elucidating the mechanism of transcriptional and translational control in eukaryotic cells. In the present paper, we present evidence that the synthesis of RNA and protein is necessary for the induction of $N$-acetylglucosamine kinase whereas the synthesis of DNA is not. Further, the strong inhibition by cordycepin (3'-deoxyadenosine) suggests that maturation of mRNA is one of the steps in the process of induction.

\section{Materials and methods}

C. albicans, strain 3100 , was obtained from the National Chemical Laboratory, Poona, India. The cells were grown in $0.5 \%$ glucose- $0.5 \%$ peptone- $0.3 \%$ $\mathrm{KH}_{2} \mathrm{PO}_{4}$ broth inoculated with an overnight culture (about 15-17h) grown in the same broth with $1 \%$ glucose. For the induction experiments, exponentialphase cells were harvested by centrifugation, washed twice with $0.2 \% \mathrm{KH}_{2} \mathrm{PO}_{4}$ solution, and resuspended in $0.2 \% \mathrm{KH}_{2} \mathrm{PO}_{4}$ containing $0.28-0.5 \% \mathrm{~N}$-acetylglucosamine. At the indicated times (Fig. 1), cells were collected by centrifugation, washed free of the sugar and stored frozen. Frozen cells $(1 \mathrm{~g})$ were suspended in $3 \mathrm{ml}$ of potassium phosphate buffer $(50 \mathrm{mM}, \mathrm{pH} 7.6)$ containing $1 \mathrm{~mm}$-EDTA and $20 \mathrm{~mm}$-2-mercaptoethanol. The cell suspension was first sonicated (in an MSE sonicator) for $1 \mathrm{~min}$ and then the broken cells were ground for $5 \mathrm{~min}$ in a mortar and pestle with fine glass powder. After centrifugation at $14000 \mathrm{~g}$ for
$30 \mathrm{~min}$, the supernatant fraction was assayed for $\mathrm{N}$-acetylglucosamine kinase activity.

$N$-Acetylglucosamine kinase activity was determined by the method of Datta (1970) and protein was measured by the method of Lowry et al. (1951) with bovine serum albumin as the standard. DNA and RNA synthesis were determined by incorporation of $\left[{ }^{3} \mathrm{H}\right]$ thymidine and $\left[{ }^{3} \mathrm{H}\right]$ uridine respectively into the trichloroacetic acid-precipitable fraction.

$\left[{ }^{3} \mathrm{H}\right]$ Uridine and $\left[{ }^{3} \mathrm{H}\right]$ thymidine were purchased from The Radiochemical Centre, Amersham, Bucks., U.K.; $N$-acetylglucosamine, cycloheximide, mitomycin C, actinomycin D and cordycepin (3'-deoxyadenosine) were purchased from Sigma Chemical Co., St. Louis, Mo., U.S.A., and hydroxyurea was a product of Calbiochem, Los Angeles, Calif., U.S.A. All other reagents were of analytical grade.

\section{Results and discussion}

The utilization of $N$-acetylglucosamine as a carbon source by $C$. albicans is as effective as that of glucose. This is evident from the similar rates of multiplication in media containing the two different sugars. Like glucose, $\mathrm{N}$-acetylglucosamine is taken up readily as the cells start to multiply after a 2-3h lag. $N$-Acetylglucosamine kinase activity is absent from the cells grown on glucose, and in all experiments extract from these cells is used as control. However, addition of $\mathrm{N}$-acetylglucosamine to the medium elicits an almost immediate synthesis of the enzyme without any detectable lag period. When the rate of enzyme formation was measured in washed-cell suspensions after the addition of $N$-acetylglucosamine, the enzyme activity increased steadily as long as $N$-acetylglucosamine was present in the medium (Fig. 1). Further, after maximum induction removal of $N$-acetylglucosamine, by either metabolic conversion (assayed by measuring the uptake of $\mathrm{N}$-acetylglucosamine) or replacement with a medium devoid of $N$-acetylglucosamine, causes a gradual decrease in enzyme activity. This 


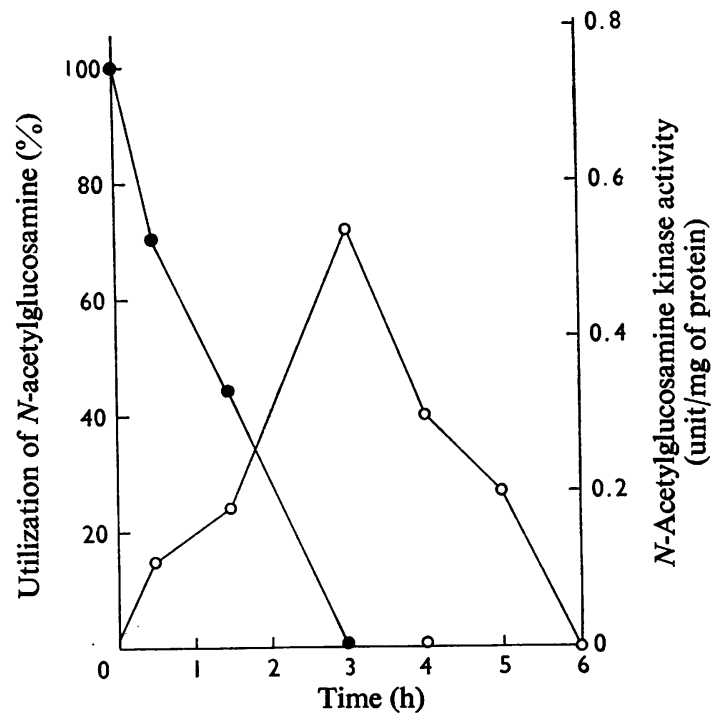

Fig. 1. Appearance of $N$-acetylglucosamine kinase in C. albicans in the presence of $N$-acetylglucosamine ( $2.8 \mathrm{~g} /$ litre $)$

Specific activity is expressed as $\mu \mathrm{mol}$ of $N$-acetylglucosamine esterified $/ 30 \mathrm{~min}$ per $\mathrm{mg}$ of protein at $37^{\circ} \mathrm{C}$ under the assay conditions. $N$-acetylglucosamine concentration of the growth medium during incubation was determined in the supernatant after centrifugation at $0^{\circ} \mathrm{C}$ to remove the cells.

Table 1. Effect of cycloheximide, actinomycin D, cordycepin, mitomycin $C$ and hydroxyurea on $N$-acetylglucosamine kinase synthesis

Cells, collected in their exponential phase of growth, were resuspended in $0.2 \% \mathrm{KH}_{2} \mathrm{PO}_{4}$ containing $N$-acetylglucosamine $(5 \mathrm{~g} /$ litre). At zero time each inhibitor was added to one group of cultures and another group of cultures received no inhibitor. At $5 \mathrm{~h}$ after the addition of $\mathrm{N}$-acetylglucosamine, cells were harvested by centrifugation and $N$-acetylglucosamine kinase activity in the cell extracts was determined.

Specific activity of $N$-acetylglucosamine kinase ( $\mu$ mol of $N$-acetylglucosamine esterified $/ 30 \mathrm{~min}$

Treatment

Non-induced cells Induced cells

+Cycloheximide

$(20 \mu \mathrm{g} / \mathrm{ml})$

+Actinomycin D

$(4 \mu \mathrm{g} / \mathrm{ml})$

+Cordycepin

$(25 \mu \mathrm{g} / \mathrm{ml})$

+Mitomycin C

$(100 \mu \mathrm{g} / \mathrm{ml})$

+ Hydroxyurea

$(200 \mu \mathrm{g} / \mathrm{ml})$
Percentage inhibition 0 0.83

0

0

0

0.83

0.90

result shows that the presence of the inducer is necessary for the synthesis of the enzyme as in the case of other inducible systems.

To find out the mechanism of $\mathrm{N}$-acetylglucosamine kinase induction several inhibitors of macromolecule (protein and nucleic acid) synthesis were tested (Table 1). The induction of $N$-acetylglucosamine kinase requires continuous protein synthesis and is prevented completely if cycloheximide (at a concentration of $20 \mu \mathrm{g} / \mathrm{ml}$, i.e. enough to stop protein synthesis in these cells) is added together with the inducer. Further, addition of cycloheximide at any time after the beginning of induction prevents any further increase in enzyme activity and causes it to level off (A. Datta, unpublished work). This result suggests that the induction involves new protein synthesis and that the inducer does not function by simply converting a precursor of the enzyme into an active form.

Actinomycin D is a potent inhibitor of RNA biosynthesis and has been used to analyse the mechanism of regulation of protein biosynthesis in many systems. Actinomycin D, at $4 \mu \mathrm{g} / \mathrm{ml}$, completely stops enzyme synthesis, when added simultaneously with the inducer or during the course of induction. This dose of actinomycin $\mathbf{D}$ does not prevent the uptake of inducer into the cells, but inhibits uridine incorporation into RNA by more then 95\%. Tomkins et al. (1966) reported a paradoxical increase in enzyme concentration in the presence of actinomycin D for inducible tyrosine aminotransferase in cultured hepatoma cells. A phenomenon sometimes termed 'superinduction' is rather frequently observed in other eukaryotic cells (Tomkins et al., 1972). In the present study, no such 'superinduction' was observed for $\mathrm{N}$-acetylglucosamine kinase in $C$. albicans in the presence of actinomycin $\mathbf{D}$.

In our induction system we have also studied the effect of cordycepin (3'-deoxyadenosine), which has been reported (Penman et al., 1970; Darnell et al., 1971) to suppress the transport of newly synthesized mRNA from the nucleus to the cytoplasm. As for actinomycin $\mathrm{D}$, cordycepin, at $25 \mu \mathrm{g} / \mathrm{ml}$, strongly inhibits the formation of new kinase. Further, this concentration of the drug specifically inhibits the incorporation of adenosine into the mRNA fraction containing poly(A) (A. Datta, unpublished work). These results agree well with the findings (Darnell et al., 1971) in HeLa cells that cordycepin suppresses the appearance of mature mRNA in cytoplasm by inhibiting the addition of a poly(A) segment to nuclear mRNA. Studies with cordycepin also emphasize the importance of transcriptional control as against translational control in induced enzyme synthesis. All these findings suggest that the induction of $\mathrm{N}$-acetylglucosamine kinase involves induced synthesis of kinase-specific mRNA and 
possibly selective promotion of gene transcription by the inducer.

The question whether DNA synthesis is required for kinase induction has been dealt with by using hydroxyurea and mitomycin $\mathrm{C}$ as specific inhibitors of DNA synthesis. Mitomycin C, at $100 \mu \mathrm{g} / \mathrm{ml}$, completely inhibits DNA synthesis (determined by incorporation of $\left[{ }^{3} \mathrm{H}\right]$ thymidine into the trichloroacetic acid-precipitable fraction), whereas only $60 \%$ inhibition (maximum) is achieved by $200 \mu \mathrm{g}$ of hydroxyurea $/ \mathrm{ml}$. Moreover, these doses do not affect the cellular RNA synthesis (determined by incorporation of $\left[{ }^{3} \mathrm{H}\right]$ uridine into the trichloroacetic acid-precipitable fraction). Inhibitors of DNA synthesis (mitomycin $\mathrm{C}$ or hydroxyurea), when added simultaneously with the inducer or during the course of induction, have no effect on $\mathrm{N}$-acetylglucosamine kinase synthesis. Further, when the inhibitors are added before induction, there is still no perceptible effect on enzyme synthesis (A. Datta, unpublished work). Thus continuous DNA synthesis is not necessary for enzyme induction and DNA synthesis before induction is not a necessary prerequisite for the formation of $\mathrm{N}$-acetylglucosamine kinase.

We thank Professor G. P. Talwar, Department of Biochemistry, All India Institute of Medical Sciences, New Delhi, India, and Dr. H. K. Das, Indian Agricultural Research Institute, New Delhi, India, for providing the laboratory facilities.

Darnell, J. E., Philipson, L., Wall, R. \& Adesnik, M. (1971) Science 174, 507-510

Datta, A. (1970) Biochim. Biophys. Acta 220, 51-60

Lowry, O. H., Rosebrough, N. J., Farr, A. L. \& Randall, R. J. (1951) J. Biol. Chem. 193, 265-275

Penman, S., Rosbash, M. \& Penman, M. (1970) Proc. Nat. Acad. Sci. U.S. 67, 1878-1885

Tomkins, G. M., Thompson, E. B., Hayashi, T., Gelehrter, D., Granner, D. \& Peterkofsky, B. (1966) Cold Spring Harbor Symp. Quant. Biol. 31, 309-313

Tomkins, G. M., Levinson, B. B., Baxter, J. D. \& Dethlefsen, L. (1972) Nature (London) New Biol. 239, 9-14

Zeleznick, L. D., Hankin, H., Boltralik, J. J., Haymann, H. \& Barkulis, S. S. (1964) J. Bacteriol. 88, 1289-1295 